\title{
Agôn
}

Revue des arts de la scène

Critiques | Saison 2010-2011

\section{Les dimensions de Madame Bovary}

À propos de Madame Bovary créé par la Compagnie Karyatides

\section{Caroline Châtelet}

\section{Q OpenEdition}

Journals

Édition électronique

URL : http://journals.openedition.org/agon/1755

DOI : 10.4000/agon. 1755

ISSN : 1961-8581

Éditeur

Association Agôn

Référence électronique

Caroline Châtelet, "Les dimensions de Madame Bovary », Agôn [En ligne], Critiques, mis en ligne le 17 juillet 2011, consulté le 23 septembre 2020. URL : http://journals.openedition.org/agon/1755 ; DOI : https://doi.org/10.4000/agon.1755

Ce document a été généré automatiquement le 23 septembre 2020

Association Agôn et les auteurs des articles 


\title{
Les dimensions de Madame Bovary
}

\author{
À propos de Madame Bovary créé par la Compagnie Karyatides
}

\section{Caroline Châtelet}

\section{RÉFÉRENCE}

Madame Bovary, d'après l'œuvre de Gustave Flaubert, adaptation en théâtre d'objet par la compagnie Karyatides.

Avignon, Festival off, Théâtre des Doms, du 8 au 28 juillet à $11 \mathrm{~h}$ (relâche le 18 juillet) Mise en scène: Agnés Limbos - Adaptation: Marie Delhaye, Françoise Lott - Comédienne: Marie Delhaye - Création sonore et régie son: Guillaume Istace - Création lumière et régie: Karl Descarreaux - Costumes: Françoise Colpé Une production de la Compagnie Karyatides. En coproduction avec la Compagnie Gare Centrale. Avec l'aide de la Communauté française Wallonie Bruxelles - Service du Théâtre.

1 Relais de la création belge wallonne, le Théâtre des Doms accueille dans sa programmation la compagnie Karyatides. Une équipe qui propose, dans un théâtre d'objets stylisé, inventif et délicat, une adaptation du grand roman de Gustave Flaubert. 
Madame Bovary, d'après Gustave Flaubert, création de la Compagnie Karyatides

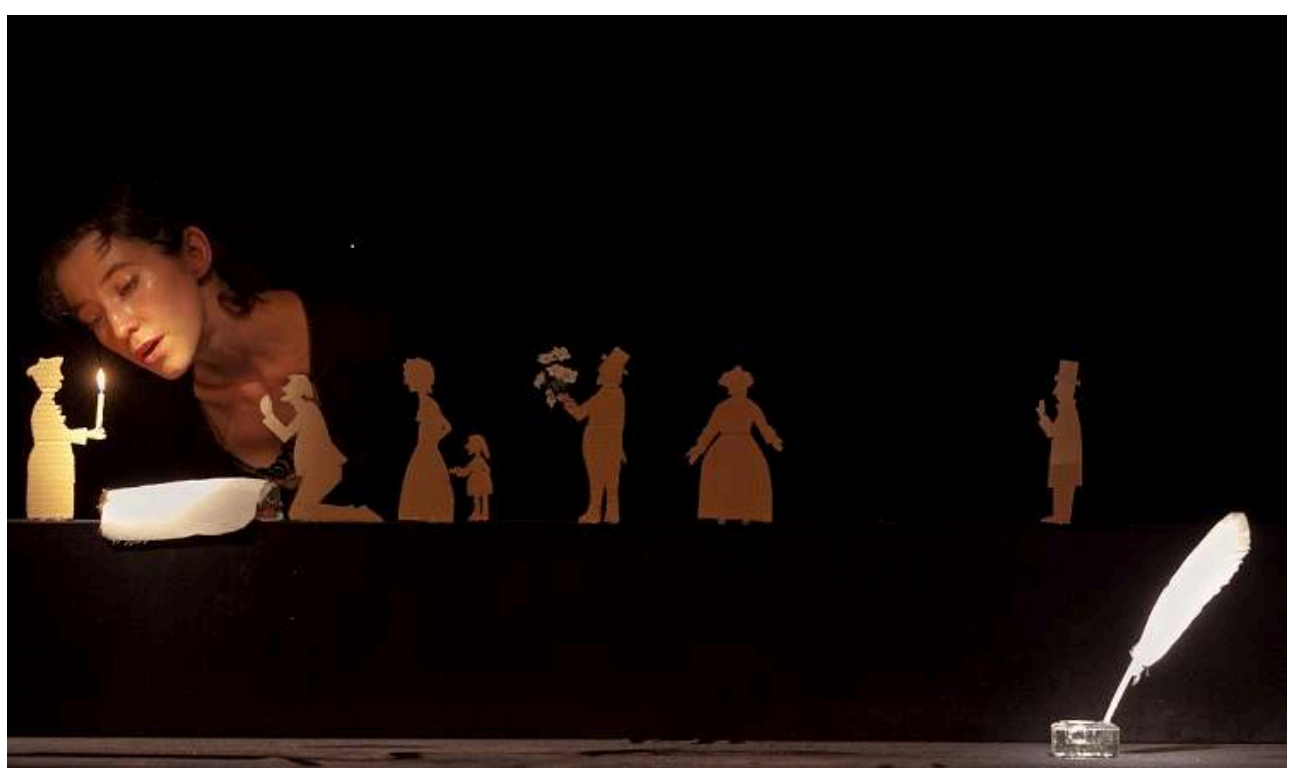

(c) Yves Gabriel

2 L'adaptation d'œuvres littéraires majeures en théâtre d'objets est aujourd'hui chose courante. Un choix qui, au-delà du récit raconté, démontre les multiples possibilités qu'offrent les arts de la marionnette, tout en déjouant du même coup le qualificatif de « mineur » trop souvent accolé à ce genre. Georges Orwell, Molière ou encore Flaubert figurent parmi les illustres auteurs convoqués pour cette édition 2011 du festival off d'Avignon. Si les réussites sont, comme toujours, plus ou moins heureuses selon les équipes, il en est une qui tient assurément ses engagements. Car en mettant en scène Madame Bovary de Gustave Flaubert, c'est une délicate et subtile version que livre la compagnie belge Karyatides. Seule en scène, la manipulatrice Marie Delhaye raconte l'histoire de cette jeune femme mariée à un médecin établi et falot. Représentée par une petite poupée aux longues robes, celle qui ne rêve que de passions intenses et de sentiments ardents étouffe rapidement dans cet univers bourgeois et conformiste, signifié par des objets stylisés en bois blancs. Mais poussée par son romantisme et son désir d'exaltation, Madame Bovary se laisse envahir par ses propres fantasmes et s'abandonne dans des aventures successives, qui la mèneront à sa perte. En adaptant ce grand classique de la littérature du dix-neuvième siècle, la compagnie resserre le récit sur l'essentiel : le rejet de " l'ordinaire " par Emma Bovary et son désir d'extraordinaire. Ce sont donc deux mondes qui cohabitent et se croisent, l'un habité d'objets et de figurines en bois blanc en deux dimensions, sans couleurs ni épaisseur et l'autre, univers coloré et vivant composé de personnages en relief. Manipulatrice autant que comédienne, Marie Delhaye donne vie avec finesse à cette histoire, endossant les différents rôles en alternance avec une bande-son, tout en faisant apparaître puis disparaître les quelques éléments nécessaires à la narration. Peu nombreux, mais n'en étant que plus essentiels et signifiants, ces objets renvoient aux étapes majeures du récit de Flaubert : le premier chagrin d'amour, la soirée à l'opéra, le verre d'arsenic... Pour autant, il s'agit bien ici d'un travail d'adaptation et la compagnie, en faisant sienne cette histoire, y apporte une tonalité toute personnelle. Ainsi, l'univers sonore propose une composition intelligente et empreinte d'humour, qui permet de soutenir autant que de décaler le récit. Et c'est cette alliance subtile et 
intelligente entre narration d'une histoire et regard légèrement distancié sur le romantisme et les sentiments les plus excessifs de l'œuvre de Flaubert qui confère à cette Madame Bovary un charme manifeste.

INDEX

Mots-clés : Avignon, Compagnie Karyatides, Festival d'Avignon, Flaubert (Gustave) 